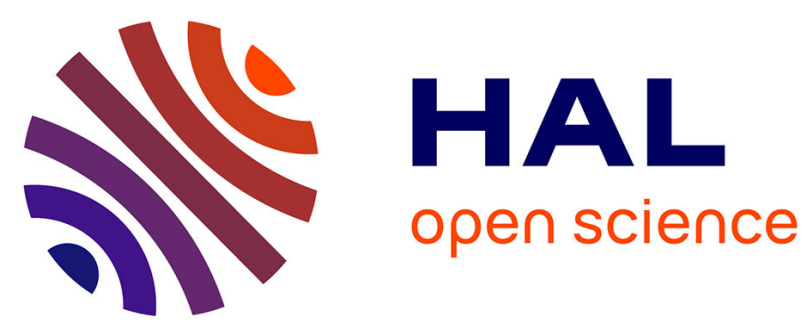

\title{
Between hope and boredom: Attending to long-term related emotions in participatory environmental monitoring programmes
}

\author{
Marine Gabillet, Isabelle Arpin, Anne-Caroline Prévot
}

\section{To cite this version:}

Marine Gabillet, Isabelle Arpin, Anne-Caroline Prévot. Between hope and boredom: Attending to long-term related emotions in participatory environmental monitoring programmes. Biological Conservation, 2020, 246, pp.10/108594. 10.1016/j.biocon.2020.108594 . mnhn-02934487

\section{HAL Id: mnhn-02934487}

\section{https://hal-mnhn.archives-ouvertes.fr/mnhn-02934487}

Submitted on 9 Sep 2020

HAL is a multi-disciplinary open access archive for the deposit and dissemination of scientific research documents, whether they are published or not. The documents may come from teaching and research institutions in France or abroad, or from public or private research centers.
L'archive ouverte pluridisciplinaire HAL, est destinée au dépôt et à la diffusion de documents scientifiques de niveau recherche, publiés ou non, émanant des établissements d'enseignement et de recherche français ou étrangers, des laboratoires publics ou privés. 


\section{Between hope and boredom: attending to long-term related emotions in participatory environmental monitoring programmes}

Authors: Marine GABILLET ${ }^{\mathrm{a}, \mathrm{b}}{ }^{*}$, Isabelle ARPIN ${ }^{\mathrm{a}}$, Anne-Caroline PREVOT ${ }^{\mathrm{b}}$

a Univ. Grenoble Alpes, INRAE, LESSEM, 2 rue de la papeterie, 38400 Saint-Martin-d'Hères, France

${ }^{b}$ Centre d'Ecologie et des Sciences de la Conservation (CESCO UMR 7204), MNHN, CNRS, Sorbonne Université, CP135, 57 rue Cuvier, 75005 Paris, France

marine.gabillet@inrae.fr

isabelle.arpin@inrae.fr

anne-caroline.prevot@mnhn.fr

${ }^{*}$ Corresponding author

\section{Introduction}

Rising concerns over environmental changes in the Anthropocene have fostered the proliferation of environmental monitoring programmes (Likens and Lindenmayer, 2018). The accuracy and success of most of these programmes are based on a high number of participantsscientists, volunteer citizens participating in their free time and professionals participating in their working time - and large spatial and temporal extents (Bonney et al., 2009). In particular, the programmes' long-term dimension is considered crucial to detecting potential changes in the surveyed ecological processes and understanding their underlying causes and their effects on, as well as the responses of, socio-ecosystems (Magnusson, 1990; Devictor et al., 2010). Such a dimension also allows modelling past dynamics and elaborating scenarios for the future (Couvet et al. 2008) and is therefore highly valued and encouraged by scientists in charge of these programmes. However, the long-term perspective comes with a number of difficulties, e.g., achieving data continuity (Ribes \& Jackson, 2013), maintaining participation (Rotman et 
al., 2012) and sustaining funding (Hughes et al., 2017). Maintaining these programmes over time thus demands strenuous work from these programmes' managers.

We focus here on the emotional dimension of this work. Emotions are increasingly acknowledged as playing a major and pervasive role in scientific activities in general (Barbalet, 2002; Parker and Hackett, 2014) and in participatory monitoring in particular (Lorimer, 2008). Researchers' strategies to address their emotions has also emerged as an important aspect of their work, e.g., in climate science (Head and Harada, 2017). In line with the literature highlighting the role of emotions and emotional work in sustaining social movements and volunteering (Goodwin et al., 2004; Jasper, 2011), we contend that attending to emotions is crucial to maintaining monitoring programmes over the long term.

The present article seeks to contribute to the burgeoning body of literature about the interplay between emotions and science (Parker and Hackett, 2014) by exploring the emotions and emotional work associated with the long-term perspectives of environmental monitoring programmes. We explored long-term related emotions and emotional work performed by the programme managers in two programmes involving participants through their professional activities in France. We chose this kind of programme rather than programmes involving volunteers participating in their free time for two reasons. First, the selected programmes form a major, albeit understudied, portion of environmental monitoring programmes. Second, which emotions are deemed socially appropriate depend on the social context (Hochschild, 1983). Feeling rules, i.e., societal norms about the appropriate type, amount and duration of feelings that should be experienced in a particular situation (Hochschild, 1979), are likely to be particularly constraining at work.

We contribute to understanding how environmental monitoring programmes can be sustained over time by addressing the following two questions: What emotions related to the programmes' long-term perspective do the managers of such programmes experience? How do 
the managers attend to these emotions? We first present a state-of-the-art summary regarding emotions, emotional work and time-related emotions before presenting the two programmes investigated, the method we used to collect and analyse the data, and our findings. We finally discuss the place of long-term related emotions in current knowledge production and their specificities in professional settings and in the work of the programme managers.

\section{Affect, science, and time}

\subsection{Affects, emotions and emotional work}

The recent affective turn in social sciences (Clough and Halley, 2007) has highlighted the role of affects and emotions in many, if not all, areas and moments of social life. It offers a fundamentally relational perspective on affects, associating the notion with the intensity of bodily encounters. Anderson (2006: 735, emphasis in original) defined affect as "a transpersonal capacity which a body has to be affected (through an affection) and to affect (as the result of modifications)". Affects can be considered "free radicals" that may combine with "more or less any aspect of life" (Anderson, 2014: 6): "things, people, ideas, sensations, relations, activities, ambitions, institutions, and any number of other things, including other affects" (Sedgwick, 2003: 19), and, we add, time. Defining affects as bodily changes to the changing situations in which people find themselves (Protevi, 2009: 33) might suggest that they

are essentially spontaneous and ephemeral. However, the capacity to be affected develops gradually through a learning process nurtured by successive interactions between humans and their surroundings (Lorimer, 2008; Peltola and Tuomisaari, 2015). Affects can thus last and have long-lasting effects.

Similarities and differences between affects and emotions have given rise to an intricate theoretical debate (see Anderson, 2006; Fox, 2015). We consider here that emotions can be grasped as a part of a broader affective flow that contributes to the making of human beings 
and their social world (Fox, 2015). Like affects, they contribute to relating people to one another, as well as to other beings and things. However, unlike affects, which are often held to be unconscious and inexpressible, emotions can be qualified and expressed (Anderson, 2006). People name the emotions they experience and identify the emotions expressed by others. We are interested in how these emotions intervene in social life and what they do (Ahmed, 2013: 4). We thus adopt a functional and relational approach to emotions that departs from physiological and individualistic perspectives.

Affects can be disciplined, modulated or even manipulated, even if always incompletely (Anderson, 2014). For instance, Hochschild (1983) showed how flight attendants are required to learn to manage their emotions when interacting with passengers, displaying some emotions while concealing others. She termed the processes by which workers manage their emotions in order to conform to employer-defined rules emotional work. Importantly, emotional work is not only about attending to one's own but also others' emotions, as it serves to create a particular emotional state in other persons (Hochschild, 1983: 7). Specific techniques are used in contemporary neoliberal societies to cause individuals to feel in a certain way (Anderson, 2016) towards, for example, urban management projects (Ernwein and Matthey, 2019). The notion of emotional work thus suggests that emotions can, to some extent, be anticipated, controlled, and even shaped. They do not necessarily spring up unpredictably and irrepressibly from situations and encounters, and they can be relatively stable and long term (Jasper, 2011).

\subsection{Emotions and emotional work in science}

Science is still commonly regarded as a realm of reason that leaves little, if any, place to emotions. However, the crucial role of emotions in scientists' everyday life has gradually been recognized and highlighted (Barbalet, 2002; Parker and Hackett, 2014; Waquet, 2019). Researchers simply cannot attend and respond to their research objects (e.g., Lorimer, 2008) or instruments (Walby and Spencer, 2012) without being attached to them affectively. Emotions 
also play a strong role in scientific collaborations (Boix Mansilla et al., 2016). Studying Resilience Alliance, an international networked organization exploring the dynamics of socialecological systems, Parker and Hackett (2012) showed how the organization of brief but intense moments of collaboration in isolated places regularly creates conditions for intellectual fusion and feeds the network's creativity and scientific productivity over time, thus allowing for its expansion and coherent development.

Studies on emotions in environmental monitoring programmes have mainly focused on programmes involving non-professional volunteers. Some have explored the volunteers' emotions related to naturalist data collection (Lorimer, 2008; Charonnet, 2020); others have highlighted the "mutual apprehension and mistrust" between participants and researchers as a source of demotivation (e.g., Rotman et al., 2012). These studies have underlined the relationship between the valence of the participants' emotions and the programmes' dynamics. This relationship is far from straightforward: for instance, Semal (2019) shows that negative emotions, such as anxiety over ecological collapse, may dispose individuals to engage in environmental activism and feed their engagement over time.

While emotions in science have started to receive scholarly attention, there is much less literature about how scientists perform emotional work. However, this is likely to be an important aspect of their work and one that increasingly relies on large inter- and transdisciplinary networks, notably in the life sciences (Parker et al., 2016). Head and Harada (2017) analysed the emotional management strategies employed by climate scientists to continue their research despite dire predictions and persisting denials, such as emphasizing dispassion, suppressing painful emotions, using humour, and switching off from work.

\section{Case studies and data collection method}


We focus on the emotions of and emotional work performed by the managers of two recent environmental monitoring programmes involving professionals. We consider managers to be all the persons involved in either coordinating the scientific research or facilitating the network of participants at diverse scales.

\subsection{Alpages Sentinelles (AS) and Propage}

Following three consecutive droughts in the Écrins National Park (French Alps), Alpages Sentinelles was launched in the 2000s to help mountain grazing systems adapt to climate change. It has gradually expanded over all national parks and natural regional parks in the French Alps, encompassing 31 mountain pastures and 37 farms at the time of writing. It brings together researchers with various disciplinary backgrounds, farming professionals (farmers and shepherds) and experts, and protected area managers, who contribute their specific knowledge and data to explore the functioning and adaptation capacity of alpine grazing systems (Dobremez et al., 2014). Protected area field staff, who are notably in charge of monitoring species and habitats, estimate the biomass of the pastures at the beginning of the grazing season; pastoral systems specialists ${ }^{1}$ evaluate the grazing pressure at the end of the summer; professional botanists carry out floristic inventories along predefined transects every five years; staff from farming organizations carry out annual surveys of the participating farms; shepherds are given rain gauges to record rainfalls on their pastures and are required to record their grazing practices, etc. Overall, AS involves some 70 people. A permanent junior researcher dedicates half of her time to the scientific coordination of the programme. She works closely with a pastoral systems specialist, a long-term employee devoting $40 \%$ of his time to the facilitation of the participant network. In each protected area involved, one or two persons devote a very variable part of their time to facilitating the network of contributors. These persons are mostly

\footnotetext{
${ }^{1}$ Pastoral systems specialists work for the development of the pastoral economy and the sustainable use of pastoral areas.
} 
long-term employees who have included tasks related to the programme into their missions. The time dedicated to the programme is either financially compensated (shepherds) or financed (staff from national parks and farming organizations). By dint of hard work, AS promoters and managers have so far succeeded in finding short-term funding to maintain the programme, with some problematic interruptions and many uncertainties.

Launched in 2011 at the national scale, Propage is one of the citizen science programmes coordinated by the French National Museum of Natural History under the banner "Vigie Nature". Unlike other programmes targeting non-professionals, this program involves professionals in the monitoring of common species of butterflies, a majority of whom are gardeners employed by the green areas departments of cities. According to the Propage scientific coordinator, some 200 gardeners were monitoring 447 sites distributed across 56 municipalities in 2018. The French Biodiversity Agency funds the position of a scientific coordinator for the three "Vigie Nature" programmes dedicated to professional nature managers, including Propage. In addition, a person hired by a partner NGO of the museum leads the national network of participants. Both are long-term employees but only work part time for Propage. They are relayed locally by the staff of the cities' green areas departments. Unlike AS, Propage does not support municipalities for the participation of gardeners in the programme.

Both programmes were designed from a long-term perspective. The programme managers saw the long-term perspective as the only solution for dealing with environmental changes such as climate change and biodiversity loss, as expressed here in the case of Propage:

"When you work on biodiversity, doing a one-year action and then stopping doesn't make sense. The long term is what makes sense in ecology, that's what's interesting. You haven't done anything with a three-year monitoring; you have no results before 10-15 years, especially when you work on butterflies!” (19/02/2018). 
The two programmes differ in several ways (geographic coverage, type of area concerned, institutional frame, types of funding), therefore offering the possibility to reflect on the factors that might influence their managers' emotions and emotional work.

\subsection{A methodological challenge: learning to talk about emotions}

Studying emotions from a relational and functional perspective, we focused on what our informants verbally declared and non-verbally expressed and paid attention to the "hesit[ation], uncertain[ty] and approximat[ion]" of their attempts to express their emotions (Mariani and Plancke 2018: 6).

We made three important methodological choices to help our informants talk about their emotions and emotional work related to the long term. First, we made the object of our research explicit, telling our informants that we were interested in the place and role of emotions in their work. Second, we established tight and trusting relationships with some of the managers and worked with them over a relatively long period of time (even if in a much shorter term than the programmes themselves) from 2015 to July 2019. This enabled us to observe the emotional work in a much diversified range of situations and to see how punctual events (e.g., the departure or arrival of other managers and participants, the success or failure of funding applications, the organization of meetings, climatic events) and evolutions of the programmes (e.g., rising number of organizations wanting to enter the programme, persisting funding difficulties) affected the managers. More importantly, the duration of the research enabled these managers to provide us with a gradually more complete, nuanced and well-articulated description of their emotions and emotional work. They, the managers, and we, the researchers, learned to reflect on and talk about emotions over the course of the research. Our third important methodological choice was to invite the managers of the two programmes to discuss their emotions and emotional work collectively. We organized two meetings to share our 
intermediate results with them. This also helped them clarify and express their emotions by comparing their own emotions to those of their colleagues and by collectively finding ways to express these emotions as accurately as possible.

Overall, we conducted formal semi-directed interviews with 24 current or former managers (see appendix for details) from several protected areas or municipalities. We asked them to retrace their involvement in the programme and to explain their status, roles, how these had evolved over time, and their relationships with all the persons involved (participants, other managers, funders, etc.). We also asked them about their emotions related to the programme's long-term perspective and about the participants' emotions and how they sought to deal with these emotions. Interviews lasted from one to two hours and took mostly place at the interviewee's workplace. We recorded and transcribed the interviews integrally. We had regular informal discussions with four of the participants working in the same city as two of the co-authors, and we took notes about these discussions. We had access to all the documents and emails concerning the two programmes, which enabled us to be aware of and participate in the programmes' activities. All of the discussions during the two collective meetings we organized were also recorded and transcribed.

We drew on all the material collected to carry out the analysis. Using qualitative software adapted to grounded theory (Strauss and Corbin, 1997), we coded the interviews, paying attention to the emotions and emotional work related to the long-term dimension of the programmes. We cross-checked the coding: most of the time, we agreed on the qualification of the emotions; when we did not, we discussed the type of emotion and sometimes returned to the informant until we could reach an agreement about the emotions expressed and the emotional work performed. We also heavily relied on our numerous field observations to make sense of the emotions expressed by our informants during the interviews. Emotions are indeed difficult to identify and interpret when detached from the thick context in which they are 
embedded. Observing the managers work over several years and participating in the activities they organized enabled us to gain inside knowledge of this context and to make sense of the emotions we captured.

\section{Between hope and boredom}

Managers of both programmes strongly expressed their concerns regarding their own and the participants' weariness, as the programmes struggled to reconcile short-term gains with a longterm scope. We observed managers succeeding in finding motivation again, as well as managers abandoning the programme. We found that they expressed and attended to two emotions related to the long term: a positive emotion, hope, and a more complex emotion, which we found more difficult to name. Turning to the literature, we discovered that the notion of boredom as described by, e.g., Barbalet (1999) or Anderson (2006), was very close to what our informants expressed.

\subsection{Hope}

One major motivation of the programme managers was the hope that working with professionals over the long term would help in taking significant action to adapt management practices to global change and biodiversity loss. Similar to the other Vigie Nature programmes, the implementation of Propage fostered the hope of informing the national debate and decisions on public policy (Couvet et al., 2008). The programme's local managers expected that it would contribute to a better integration of biodiversity in the management of urban green spaces:

"Our goal is not to find a super rare butterfly, even if I would be very happy to find a super rare butterfly, but the goal is at least to see that there are butterflies. Just knowing that there are butterflies is better than what we have done so far. The choice of butterflies was a good one, beyond the symbol, because in the end there are no butterflies that are 
[useful in horticulture]. They are either parasitic or neutral. So if we can try to keep a bug that isn't useful, (...) maybe it will be easier to act in favour of biodiversity" (07/01/2014).

In the case of AS, fostering the dialogue between the multiple actors involved in grazing systems, particularly between farming professionals and protected area managers, appeared crucial to adapting grazing practices to climate change. The programme's managers explained that, unlike other issues such as wolf predation, climate change can bring actors together, provided that enough time is available for them to understand each other:

"What matters to me is that Alpages Sentinelles is a space for dialogue. I think that's what's beautiful about it. I see my position as that of a researcher accompanying collective reflection and who is here to bring elements of methodology into practice, and time to think and produce things that improve the ability to enhance adaptability and to make people understand each other better" $(09 / 10 / 2017)$.

Another important source of motivation for managers was the prospect of new encounters, with the long-term dimension being perceived as a promise to extend the network:

"I have made extraordinary encounters in AS, which I would never have made otherwise, and I still hope to make others. For me, the driving force behind this whole system is tomorrow’s encounters!" (25-06-2019)

The managers also expressed hope that the long-term perspective would create knowledge about complex social-ecological processes, whereas the current context of short-term planning and project-based research does not foster this type of knowledge. They saw the programmes' duration as a rare chance to take the time to investigate and understand such intricate phenomena as the adaptation of plant communities and grazing systems to climate change (Dobremez, 2014; Nettier, 2016). 
Finally, involving nonprofessional scientists in the production of scientific knowledge fostered the hope that the programmes could help fill the gap between science and society. In the case of AS, the long-term perspective was seen as an opportunity to build synergies across various knowledge systems. A manager of the programme insisted on the importance of this long-term collaborative dimension:

"We had been working on the topic for nearly ten years so... It doesn't come at once. It's really a question of maturation..., which takes time, and facilitates exchanges with all the actors" (30/11/2015).

However, such hopes coexist with a feeling of boredom, especially when managers face uncertainties or difficulties.

\subsection{Boredom}

The weariness and anxiety the managers expressed came from the repetition of tedious tasks and the eruption of uncertainties or difficulties regarding the programme outcomes and outreach, which questioned the programme's significance. In such moments, what managers described can be compared to boredom, a complex feeling associating weariness and anxiety due to the repetitive nature of the programme and its perceived meaninglessness.

\subsubsection{Weariness}

The lack of long-term funding caused much of the managers' weariness, as it forced them to regularly apply for additional funding, a task perceived as particularly tedious. In particular, AS managers declared spending much of their time submitting complex funding applications. They resented the gap between discourses about the importance of long-term programmes and the near impossibility of obtaining long-term funding, especially when they were employed on short-term contracts and had no clear perspectives on their own professional future. The 
managers also resented devoting ever more time to cost justification and pointed to the kilos of supportive documents they had to copy, handle and archive every year:

"Funders tell me AS is great, but then when it comes to paying for it, there is nobody. Partners tell me it's great, but overall, they are happy that there's someone who takes care of all the boring stuff, etc. I'm pretty worn out!" (09/10/2017).

Propage managers also expressed weariness due to a (now partly solved) lack of resources:

"I'm a little worn out right now! It hasn't taken off! I've been at Vigie Nature for years, we've been talking about automatic feedback, we promised them to observers and they still don't come, uh we're constantly justifying ourselves, making promises! Uh... and in the meantime, observers don't have their feedback!" $(19 / 02 / 2018)$

The repetition of the same activities year after year was the managers' main source of weariness. They constantly had to recruit and train new participants because of the high attrition rate, and they sometimes struggled to maintain the continuity of the programme and associated protocols:

"Every time there's a new person, it's good, it's rewarding too! But at the same time, uh... they're going to question a number of things, they're going to... yeah! And so pff...[laughs]" (08-03-2018).

They also regarded the elaboration of annual reports and documents presenting their programme's progress as a repetitive and wearisome task in both programmes. They considered giving feedback to the participants to be crucial to maintaining a high level of interest, so they spent much time preparing such feedback. For instance, they sent farmers participating in AS an annual written account of their practices. However, they felt that such accounts and reports actually generated little interest and consideration over the years: 
"The farmers know it, you see! There's no need for... so uh... it has the opposite effect a little bit and we almost seem... 'scientists play with all this but'... it's not very... not motivating for the farmers, nor rewarding for us, you know! And so you lose your motivation also because you don't feel... really.... What's the point of what you do, it's not very rewarding!” (20-12-2017)

The managers also reported that he participants were feeling tired. They noted that collecting data over the long term was complicated, especially when it was physically demanding, as in the case of AS, where participants have to work in steep slopes and/or in cold and wet weather (notably in the Northern Alps):

"Technicians who dedicate 40 or 50 days a year to the programme need to have perspectives, know where things are going, etc. and these are the ones who first expressed lassitude" (09/10/2017).

The managers also noticed data collector fatigue when there was not much to observe. Guaranteeing the scientific robustness of the data or their operational utility implied elaborating sampling protocols covering a diversity of natural habitats, including habitats little propitious to the species investigated or to biodiversity in general. In the case of Propage, some transects had been set up in areas of the cities with very few butterflies:

"It's complicated for the guys to carry on for a long time if they never see anything! First, they don't learn to see and then despite everything, what remains in everyone's head is that you have to see something to make it interesting, even if it's important for the results and analyses to go everywhere" (19/02/2018).

\subsubsection{Loss of meaning and anxiety}

Both the lack of time and difficulties in linking observations to causal effects or achieving expected practical outcomes weakened the managers' faith in the capacity of the programmes 
to help them deal with climate change or biodiversity issues and nourished their anxiety. Local managers felt that environmental changes were difficult to detect and, if detected, to interpret, as these changes were influenced by a very broad range of intricately interacting factors. In the case of AS, in particular, the effects of climate change turned out to be extremely difficult to disentangle from the effects of, e.g., changes in common agricultural policy or wolf predation.

However, in both programmes, participants were impatient to obtain clear results, which affected the managers and made them anxious:

"This long-term dimension is intended and expected, but when we set up programmes, we are asked from the very first year: 'What are the trends?' And when you say: 'It takes time, it doesn't happen overnight', you feel a certain frustration... They want the long term but there is an immediate expectation of results" (30/11/2018).

Moreover, managers believed that merely obtaining scientific results was not sufficient in the professional setting of these programmes. The results had to be operational and lead to practical applications:

"You can't afford realizing after twenty years that what you've done was useless, it's not possible in my professional culture" (30/11/2018).

They feared that participants would give up if the long-term scientific perspective could not be reconciled with the production of short-term operational results:

"If it's about collecting data for research and having no impact on grazing systems, pastoral services will play the game for one year or two and then they will say: 'We are going to stop working for you, we're not here... even if you pay us uh... we're not interested.'... That's not the point!" (09/10/2017) 
However, the managers did not clearly see how the programmes could influence managing practices, either because they did not know how to translate results into operational terms or because their attempts to change management practices were criticized. For instance, some Propage managers saw their efforts to adjust their gardening practices thwarted by the opposition of residents or colleagues:

"What I find frustrating is that... on the one hand I'm told: 'We'll be able to do things about biodiversity' and as soon as a [local resident] complains, bang! We destroy everything overnight!" (09/11/2017)

In addition, some managers were concerned about the potential use of the programmes to justify practices they deemed undesirable, such as the irrigation of mountain pastures:

"I would be a little embarrassed to have contributed to AS and to be told: since you participated you have to accept everything. It reinforces my fear that our involvement could serve to justify practices we do not support” (11-06-2019).

Beyond the uncertainty about the programmes' contribution to the sustainability of management practices, what caused the managers anxiety was that mistakes, misunderstandings and inappropriate choices could have far-reaching consequences in long-term programmes:

"One day they (the shepherds) will realize that we can't process the data from their rain gauge, it will come back like a boomerang. I'm a little afraid of that but..." (0910-2017).

Interestingly, the managers were not only worried about technical mistakes but also about relational difficulties that could threaten the programmes over the long term:

"This idea of the long term is not only expressed through monitoring activities, it is also relational time which is long.... If you miss an interaction at one moment, the consequences will last over the whole duration of the project" (30/11/2018). 


\subsubsection{The restlessness of boredom}

Altogether, weariness and anxiety fuelled one another and led to boredom, an emotion that arises when people cannot make sense of what they are doing and may emerge in the context of repetitive activities. Boredom led two managers to quit the programme they were in charge of after several years of intensive commitment. The Propage national manager left her position in May 2019 to embark on an entirely different career path. After a long period of hesitation, one AS manager eventually decided to resign from his position in October 2017. He, too, chose a job he found more meaningful:

"The impression of just generating a lot of hot air bothers me and this is coupled with an... administrative burden, uh... also unbearable and... I do find my subject exciting... but I find that... I can't bear the system around it! And so that's it! I see that the... it doesn't change, on the contrary it gets worse.... I can't make sense of this! For a day of work where I'm going to say ah! I worked well, it was interesting, it progressed and it was... it makes sense and I had fun, there are too many days when I think it's stupid!" (09/10/2017).

However, the boredom of the participants and the managers did not just incite the managers to leave the programmes and find meaningfulness in other activities. It also encouraged them to make the programmes more meaningful.

\section{Feeding hope and alleviating boredom}

The boredom they felt and recognized in the participants encouraged the managers of both studied programmes to find ways of feeding hope and alleviating boredom linked to weariness and anxiety.

\subsection{Making protocols less wearisome and more meaningful}


The managers sometimes dismissed expressions of weariness that they considered inappropriate in a professional setting. However, they more often envisaged several ways of rendering the protocols less wearisome. For instance, they revised some protocols, which required a trade-off between the need for data continuity and the need for alleviating the weariness and meaninglessness of some protocols:

"It makes sense to work in the long term for a project like AS on climate change. But we must give ourselves time to evaluate, to, uh... revise the protocols. It's been ten years and... we can't keep going like this with our noses in the handlebars and... finally without revising a few things!"” (08/03/2018).

For example, AS managers first tested a simplified version of the annual survey of farms participating in the programme before suspending that survey until they could assess its relevance and most appropriate modalities. The survey initially included a number of very detailed questions and generated much tedious work to collect and sort out the data without people knowing precisely how to interpret the data and relate them to other data. In turn, some local Propage managers enriched the identification documents given to the gardeners with local species of butterflies to make the data collection more accurate for the local scale and enhance the gardeners' pleasure with learning. The AS managers also counted on technological solutions to reduce the tediousness of some protocols. For instance, they considered using remote sensing rather than fieldwork to evaluate the biomass on mountain pastures. Moreover, they envisaged extending the monitoring to mountain pastures where particular climatic events (e.g., a severe drought) had occurred, rather than just waiting for climatic events to happen on the mountain pastures initially selected.

\section{2. "Finding the short term in the long term"}


Although they thought that the programmes could not deliver actionable results for years or even decades, the managers tried to obtain and present useful intermediate results in the short term. As one of them put it, "we're working on an endless task; we need to find the short term in the long term." One way of reconciling the long-term perspective with the need for short-term outcomes was to concentrate on databases and methodological and synthesis documents. AS managers created a common standardized database where the data from the various protocols could be stored. They also produced a brochure about climate change and a method to diagnose each pasture's vulnerability to climate change, which they disseminated to all the participants, funders and beyond:

"We continue our monitoring activities, but in parallel we do not stop there, we are able to produce things without waiting twenty years! And so we show the data collectors that they haven't worked for five years for nothing.... And we will release at the beginning of the year a brochure that proposes a methodological approach to integrate the issue of climate change into a pastoral diagnosis.... It gives something concrete" (20/12/2017).

\subsection{Creating hot moments}

Another way of alleviating boredom and feeding hope was to create "hot moments" when all the participants and funders could meet. By breaking the programmes' routine, showing that something was actually happening, and celebrating what had been achieved so far, such moments reenergized the participants and managers. The intensity and conviviality of the meetings compensated for the boredom that had accumulated:

"At one point, the programme [AS] was really in poor shape. We then organized a big meeting in Gap, everybody was re-energized, it was a strong symbolic moment, it made sense again, we made some progress, we set up new deadlines. We were 
facing emotions that were not illegitimate and had to find ways of revitalizing the programme" (27/05/2019).

"Days like this [local Propage training sessions] really make us feel better, they're liberating! Everybody returns to their team in high spirits" (24/05/2018).

Another hot, albeit much less visible, moment consisted of a "funders' conference" convened by AS managers together with other participatory programmes in the Alps to secure the programme's budget and avoid having to submit funding applications every two or three years. This meeting gathered the regional and national institutions that could contribute to supporting AS. Even if their efforts were not yet fruitful at the time of writing, the managers hoped that this initiative could help them obtain more sustainable funding.

\section{Discussion and concluding remarks}

This study offers an emotional approach to running participatory environmental monitoring programmes and presents three specificities.

First, it focuses on the long-term perspective of these programmes, which the scientific community considers essential to face global changes. We are interested in the affective dimension of time (Johnsen et al., 2019) and, more specifically, in the emotions generated by working from a long-term perspective rather than in how emotions alter our sense of time (Droit-Volet and Meck, 2007). Throughout our extended qualitative survey, we went back and forth between interviews, field observations and literature readings. Inductively, we progressively highlighted two time-related important emotions here, i.e., hope and boredom, which coexist with varying intensities. Acknowledging and attending to these emotions are key aspects of the work of the programme managers. 
Hope is the emotion people experience when, despite the indeterminacy of the future, they are convinced that something might improve the situation currently deemed unsatisfactory (Lazarus, 1991: 282-283; Anderson, 2006). It corresponds to what Bloch (1986 [1954]) has termed the "not-yet". Hope has been particularly discussed in the field of conservation sciences. Many researchers working on biodiversity and climate change issues call for the promotion of hope to counteract the despair characterizing their research community (Swaisgood and Sheppard, 2010), and to build on its potential influence on society and politics (Garnett and Lindenmayer, 2011).

Our results confirm the importance of hope in such scientific activities. New ways of doing science, such as the development of a democratic deliberative approach to scientific collaborations supported by the Millennium Ecosystem Assessment ${ }^{2}$, can enhance researchers' hope despite disappointing results thus far and remaining scientific difficulties (Norgaard, 2008). The long-term dimension of the monitoring programmes we investigated also generates specific hopes that are deemed critical in an era of global changes: understanding complex ecological processes; establishing collaborations between scientists and actors from outside academia; and synergies between knowledge systems, as such achievements can only be obtained over long time spans.

Boredom, which occurs when there is "a felt suspension of this hope (for more life or for more to life)" (Anderson, 2004:751), is a type of anxiety that appears when people cannot make sense of what they are doing. It may be difficult to distinguish from other experiences of time such as ennui (Barbalet, 1999): ennui refers to a feeling of acceptance or resignation, while boredom is a restless and irritable feeling about an absence of interest (Barbalet, 1999: 634-635). Accordingly, boredom, but not ennui, pushes someone to act by giving more meaningfulness

\footnotetext{
${ }^{2}$ https://www.millenniumassessment.org
} 
to a situation or an activity (Barbalet, 1999; Johnsen, 2016) and is thus far from being passive or leading to passivity. Boredom has been given different places in science. Barbalet (1999: 640) noted that scientists seldom report boredom; being based on explicitly formulated problems, scientific activities, he presumes, are necessarily meaningful and, therefore, cannot be boring. However, Spencer and Walby (2013) highlighted that boredom may emerge in the context of highly repetitive activities, which is the case for many scientific activities.

Boredom is rarely associated with knowledge production activities but more with late capitalist societies (Gardiner and Haladyn, 2016) or with specific settings such as prisons (Johnsen et al., 2019). Our study contributes, then, to revising the place of boredom in scientific knowledge production activities. Contrary to Barbalet's (1999) findings, we found that these activities can be boring, not only because they are often repetitive but also because of the difficulty of making them meaningful. We thus concur with some rare previous studies about experiences with boredom in knowledge work and science. Costas and Kärreman (2015) found knowledge workers in large consultancy firms to be bored, against the expectation that their work fosters creativity, autonomy, learning, etc., and against the work's glamourous image. Donnelly (2014: 481) showed that astronomy as practised in the professional observatories of the nineteenth century was "at the vanguard of boredom": in this case, boredom notably came from the standardization of observation practices, which left little room for personal initiative but was also what made astronomy a successful science. In the programmes we investigated, boredom did not solely stem from standardization processes; it also had to do with the difficulty of interpreting particularly complex data and of making them operational in a professional context. Far from excluding one another, science and boredom can thus go together, and their relationships certainly deserve to be closely looked at in a diversity of situations.

Another interesting point here concerns the relationship between hope and boredom. At first sight, they seem to be opposed to one another, with hope having a positive valence and boredom 
a negative one. However, both of them might provide the impetus to change things and open up new possibilities. Boredom might also clearly lead to the opposite. Anderson (2006) notes that it might be the case for hope as well, but we found no compelling example of this in our material. This might be due to the fact that Anderson talks about a generic hope (life will improve), that can lead to accept things as they are, whereas the programme managers have more specific and concrete hopes (e.g. better integrating biodiversity in the management of urban green spaces). Most importantly, hope and boredom interact with one another, forming what Jasper (2011) has called a "moral battery", i.e., a combination of a negative and a positive emotion driving action forward. Hope that the programmes' promises will come true helps participants put up with boredom in their activities; in turn, this boredom helps in finding solutions to give more meaning to the present and make the desired future more likely.

Second, we investigated environmental monitoring programmes in a professional setting. We demonstrated that emotions are also important in this context, not only in programmes involving volunteers participating in their free time. Our informants told us they felt relatively free to express their emotions in their daily professional activities: feeling rules in this professional context are not as strict as those found, e.g., by Hochschild (1983) for flight attendants and more generally for workers interacting with the public. However, being professionals themselves and working with professionals clearly shapes the managers' emotional work regarding their own and the participants' emotions. For instance, enjoying oneself and having fun are not enough to make the programmes meaningful and can even appear as drawbacks in a professional setting. Managers have to demonstrate the programmes' operationality and capacity to improve the sustainability of management practices. Involving non-academic professionals in long-term monitoring programmes thus appears particularly challenging, as it requires reconciling the long-term dimension with a strong expectation of short-term operational results. 
Third, we studied these emotions from the managers' viewpoint, whereas others (e.g., Lorimer, 2008) have focused on the participants' emotions. This enabled us to shed light on how the managers seek to enhance hope and alleviate boredom; this is an important, albeit less visible, part of their work. The emotional work they perform is variegated. It includes giving feedback to participants, which has become a principle of citizen science (Robinson et al., 2018) but is not limited to that. It even seems that giving feedback too often can be counterproductive for long-term programmes, if it gives the impression that no change ever happens. Rather, the managers strive to create "the short term in the long term". This encompasses a range of practices, such as creating databases, elaborating diagnosis methods, and convening meetings, which, at first sight, may appear merely technical or social but do have an emotional dimension. They also adapt their emotional work to the programmes' specificities. For instance, they addressed the participants' boredom by simplifying a protocol in AS and by enriching a protocol in Propage. This points to the impossibility of defining emotional recipes: what enables the maintenance of environmental monitoring programmes in the long term is not only scientific and technical skills but just as much the managers' personal abilities to attend to their own emotions as well as those of the participants. This requires qualities, such as sensitivity, creativity, and perseverance, which are insufficiently acknowledged and rewarded. Our focus on emotions thus contributes to underlining the crucial role of managers and stresses their paradoxical and more than uncomfortable situation, as they are expected to maintain programmes in the long term while being themselves hired on a short-term basis and/or having to juggle with short-term funding. One condition for enabling long-term monitoring programmes, we argue, is to enable their managers to carry out their work in good conditions, which means long-term contracts and funding.

While long-term participatory environmental monitoring programmes are currently encouraged, our study shows that, overall, their management raises serious emotional 
difficulties. One fundamental reason for this, we believe, is that these programmes seek to reconcile two demands on scientific practice: openness to non-academics, whose interest in the programmes must be continuously nurtured, and a long-term perspective. This is particularly difficult to achieve when the programmes involve professional volunteers, who expect the programmes to deliver applicable results in the short term. Claiming that "another science is possible", Stengers (2013) wrote a "manifesto for slow science". Long-term environmental programmes are definitely slow: it can take decades before they yield interesting results for science, let alone for society. We contend that maintaining such programmes is possible only if close attention is paid to the ambivalent emotions and emotional work associated with their long-term dimension.

Finally, we would like to stress that the managers appreciated discussing their emotions and emotional work both with us and with other managers facing similar situations. Talking about emotions in the professional sphere remains uncommon, and it takes time to create conditions conducive to the identification and expression of emotions. Acknowledging the importance of emotions and emotional work related to the long-term perspective of monitoring programmes and providing their managers with opportunities to discuss this dimension of their work are key to better understanding the challenges of monitoring the environment in the long term and to overcoming the difficulties of such work. Discussing emotions collectively, rather than leaving emotions to the sole responsibility of programme managers, would help prevent participatory programmes from ending after only a few years, as is often the case today.

\section{Acknowledgement}

We warmly thank all our informants for discussing their emotions and emotional work with us. We are also grateful to the editor and an anonymous reviewer for their supportive and helpful comments on an earlier version of this paper. 


\section{Funding}

This work was supported by the Long-Term Socio-Ecosystem Research platform LTSER “Zone Atelier Alpes”, a member of the ILTER-Europe network.

\section{References}

Ahmed S. (2013). The cultural Politics of Emotion. Edinburgh, Edinburgh University Press.

Anderson B. (2004). Time-stilled space-slowed: how boredom matters. Geoforum, 35(6), 739754.

Anderson B. (2006). Becoming and being hopeful: towards a theory of affect. Environment and planning $d$ : society and space, 24(5), 733-752.

Anderson B. (2014). Encountering Affect: Capacities, Apparatuses, Conditions. Farnham, UK: Ashgate.

Anderson B. (2016). Neoliberal affects. Progress in Human Geography, 40(6), 734-753.

Barbalet J. M. (1999). Boredom and social meaning. The British journal of sociology, 50(4), 631-646.

Barbalet J. M. (2002). Science and emotions. The Sociological Review, 50 (S2), 132-150.

Bloch E. (1986). The Principle of Hope. (three vols). Oxford: Blackwell.

Boix Mansilla V., Lamont M., \& Sato K. (2016). Shared cognitive-emotional-interactional platforms: markers and conditions for successful interdisciplinary collaborations. Science, Technology, \& Human Values, 41(4), 571-612.

Bonney R., Cooper C. B., Dickinson J., et al. (2009). Citizen science: a developing tool for expanding science knowledge and scientific literacy. BioScience, 59(11), 977-984. 
Charonnet E. (2020) «De prises en (sur)prises, l'attachement du lépidoptériste ou comment « contacter» un papillon. », ethnographiques.org, 38.

Clough P. T., \& Halley J. (2007). The Affective Turn: Theorizing the Social. Durham, NC \& London: Duke University Press.

Costas J., \& Kärreman D. (2015). The bored self in knowledge work. Human Relations, 69(1), $61-83$.

Couvet D., Jiguet F., Julliard R. et al. (2008). Enhancing citizen contributions to biodiversity science and public policy. Interdisciplinary science reviews, 33(1), 95-103.

Devictor V., Whittaker R. J., \& Beltrame C. (2010). Beyond scarcity: citizen science programmes as useful tools for conservation biogeography. Diversity and distributions, 16(3), 354-362.

Dobremez L., Nettier B., Legeard J. P. et al. (2014). Les alpages sentinelles. Un dispositif original pour une nouvelle forme de gouvernance partagée face aux enjeux climatiques. Journal of Alpine Research, 102-2.

Donnelly, K. (2014). On the boredom of science: positional astronomy in the nineteenth century. British Journal for the History of Science, 47(3), 479-503.

Droit-Volet S., \& Meck W. H. (2007). How emotions colour our perception of time. Trends in cognitive sciences, 11(12), 504-513.

Ernwein M., \& Matthey L. (2019). Events in the affective city: Affect, attention and alignment in two ordinary urban events. Environment and Planning A: Economy and Space, 51(2), 283301.

Fox, N. J. (2015). Emotions, affects and the production of social life. The British Journal of Sociology, 66(2), 301-318. 
Gardiner M. E., \& Haladyn J. J. (Eds.) (2016). Boredom studies reader: Frameworks and perspectives. London: Taylor \& Francis.

Garnett S. T., \& Lindenmayer D. B. (2011). Conservation science must engender hope to succeed. Trends in Ecology \& Evolution, 26(2), 59-60.

Goodwin J., Jasper J. M., \& Polletta F. (2004). Emotional dimensions of social movements. In Snow D. A., Soule S. A., \& Kriesi H. (Eds) The Blackwell companion to social movements (pp. 413-432). Oxford: Blackwell Publishing Ltd.

Head L., \& Harada T. (2017). Keeping the heart a long way from the brain: The emotional labour of climate scientists. Emotion, Space and Society, 24, 34-41.

Hochschild, A. R. (1979). Emotion work, feeling rules, and social structure. American journal of sociology, 85(3), 551-575.

Hochschild, A. R. (1983). The Managed Heart: Commercialization of Human Feeling. Berkeley: University of California Press.

Hughes B. B., Beas-Luna R., Barner A. K. et al. (2017). Long-term studies contribute disproportionately to ecology and policy. BioScience, 67(3), 271-281.

Jasper, J. M. (2011). Emotions and social movements: Twenty years of theory and research. Annual Review of Sociology, 37(14),1-19.

Johnsen R. (2016). Boredom and organization studies. Organization Studies, 37(10), 14031415.

Johnsen R., Berg Johansen C., \& Toyoki, S. (2019). Serving time: Organization and the affective dimension of time. Organization, 26(1), 3-19.

Lazarus R. S. (1991). Emotion and adaptation. New-York: Oxford University Press. 
Likens G., \& Lindenmayer D. (Eds.) (2018). Effective ecological monitoring. Clayton, Vic.: CSIRO publishing.

Lorimer J. (2008). Counting corncrakes: The affective science of the UK corncrake census. Social Studies of Science, 38(3), 377-405.

Magnuson, J. J. (1990). Long-term ecological research and the invisible present. BioScience, 40(7), 495-501

Mariani L., \& Plancke C. (Eds.) (2018). (D)écrire les affects : perspectives et enjeux anthropologiques. Paris: Editions Pétra.

Nettier B. (2016). Adaptation au changement climatique sur les alpages. Modéliser le système alpage-exploitations pour renouveler les cadres d'analyse de la gestion des alpages par les systèmes pastoraux (Doctoral dissertation, Université Blaise Pascal-Clermont-Ferrand II).

Parker J. N., \& Hackett E. J. (2012). Hot spots and hot moments in scientific collaborations and social movements. American Sociological Review, 77(1), 21-44.

Parker J. N., \& Hackett E. J. (2014). The sociology of science and emotions. In Stets J. E., \& Turner J. H. (Eds) Handbook of the Sociology of Emotions: Volume II (pp. 549-572). Dordrecht: Springer.

Parker J. N., Vermeulen N., \& Penders B. (Eds.) (2016). Collaboration in the new life sciences. London: Ashgate.

Peltola T., \& Tuomisaari J. (2015). Making a difference: Forest biodiversity, affective capacities, and the micro-politics of expert fieldwork. Geoforum, 64, 1-11.

Protevi, J. (2009). Political Affect. Connecting the Social and the Somatic. Minneapolis, London: University of Minnesota Press. 
Ribes D., \& Jackson S. J. (2013). Data bite man: The work of sustaining a long-term study. In Gitelman L. (Ed.) “Raw data” is an oxymoron (pp. 147-166). Cambridge: Le MIT Press.

Robinson L. D., Cawthray J. L., West S. E. et al. (2018). Ten principles of citizen science. In Hecker S., Haklay M., Bowser A., Makuch Z. et al. (Eds.) Citizen Science: Innovation in Open Science, Society and Policy (pp. 27-40). London: UCL Press.

Rotman D., Preece J., Hammock J. et al. (2012). Dynamic changes in motivation in collaborative citizen-science projects. Proceedings of the ACM 2012 conference on computer supported cooperative work, 217-226.

Sedgwick E. K. (2003). Touching feeling: Affect, pedagogy, performativity. Durham: Duke University Press.

Semal L. (2019). Face à l'effondrement. Militer à l'ombre des catastrophes. Paris: PUF.

Spencer D. C., \& Walby K. (2013). Neo-tribalism, epistemic cultures, and the emotions of scientific knowledge construction. Emotion, Space and Society, 7, 54-61.

Stengers, I. (2013). Une autre science est possible! Manifeste pour un ralentissement des sciences. Paris: La Découverte.

Strauss A., \& Corbin J. M. (1997). Grounded theory in practice. Thousand Oaks: Sage.

Swaisgood R. R., \& Sheppard J. K. (2010). The culture of conservation biologists: show me the hope! BioScience, 60(8), 626-630.

Walby K. and Spencer D. (2012). How emotions matter: objects, organizations, and the emotional climate of a mass spectrometry laboratory. In D. Spencer, K. Walby and A. Hunt (Eds). Emotions matter: a relational approach to emotions (pp. 181-200). Toronto: University of Toronto Press.

Waquet, F. (2019) Une histoire émotionnelle du savoir. XVII ${ }^{e}-X X I^{e}$ siècle. Paris: CNRS. 